\title{
AORTIC ARCH ORIGIN OF THE VERTEBRAL ARTERY MAY HAVE CLINICAL IMPLICATIONS
}

Julius A. Ogeng'o DSc, Kevin W. Ongeti, Msc

Department of Human Anatomy, University of Nairobi. P.O Box 00100 - 30197; www.uonbi.ac.ke

The vertebral artery usually arises from the $1^{\text {st }}$ part of the subclavian artery. Variant origin may include the aortic arch, common, internal or external carotid arteries or a branch of the subclavian artery. Origin from the aortic arch, which is the most common, occurs in up to $22 \%$, but most frequently in $2-8 \%$ cases (Al Okaili and Schwartz, 2007; Lale et al., 2014; Yuan, 2016). The prevalence of this variation in African Populations is within the range of those in Indo Asian and Caucasian populations (Table $1)$.

The variations occur more commonly on the left and among females (Einstein et al., 2015). The aberrant origin of the vertebral artery from the aortic arch has an embryological basis. Usually the first part of the vertebral artery arises from the $7^{\text {th }}$ intersegmental artery. Origin from the aortic arch may occur when it arises from persistence of the $6^{\text {th }}$ intersegmental artery and a segment of the dorsal aorta which usually degenerates (Lale et al., 2014; Yuan, 2016; Keet et al., 2019).

Origin of the vertebral artery directly from the aortic arch is associated with atherosclerosis (Poonam et al., 2010; Ughade et al., 2012), cerebrovascular events, cerebral aneurysms and dissection of the vertebral artery. Such vertebral artery dissection is usually associated with hemorrhagic or ischemic posterior circulatory stroke. Secondly, it is important during thoracic, head and neck surgical procedures especially those involving the aortic arch, subclavian, carotid arterial systems and the esophagus (Yamashimo et al., 2010; Gabrielli and Rosati, 2013; Lale et al., 2014; Yuan, 2016).

Table 1: Incidence of direct aortic arch origin of vertebral artery in various populations

\begin{tabular}{|l|l|l|}
\hline Reference & Population & Incidence (\%) \\
\hline Alsaif and Ramadan, 2010 & Arabian & 22.2 \\
\hline Berko et al., 2009 & American & 6.1 \\
\hline Bhatia et al., 2005 & Australian & 7.4 \\
\hline Bhattarai and Poudel, 2010 & Nepalese & 7.0 \\
\hline Budhiraja et al., 2013 & Indian & 17.2 \\
\hline Einstein et al., 2016 & American & 14.8 \\
\hline Gielecki et al., 2004 & Polish & 6.8 \\
\hline Keet et al., 2019 & South African & 6.7 \\
\hline Makhanya et al., 2004 & South African & 1.7 \\
\hline Matula et al., 1997 & Austrian & 3.0 \\
\hline Natsis et al., 2005 & Greek & 0.79 \\
\hline Nelson and Sparks, 2001 & Japanese & 4.1 \\
\hline Nizanowski et al., 1982 & Polish & 3.1 \\
\hline Ogeng'o et al., 2010 & Kenyan & 6.2 \\
\hline Shin et al., 2008 & Korean & 8.1 \\
\hline Tapia et al., 2015 & Chinese & 4.85 \\
\hline Voster et al., 1998 & South African & 5.0 \\
\hline Yeri et al., 2011 & Argentinian & 7.3 \\
\hline & & \\
\hline
\end{tabular}


Thirdly, it may be associated with other vascular variations, such as retro - esophageal right subclavian artery and termination of the thoracic duct on the right side, which may further complicate surgery (Nathan and Seidel, 1983). Fourthly, when the vertebral artery originates from the aorta, it is commonly narrower and longer than its counterpart (Panicker, et al., 2002). This may be mistaken for pathological narrowing.

The article by Mutalife et al (2019) in the current issue of the Anatomy Journal of Africa therefore constitutes a valuable addition to literature on the anatomical variations of the vertebral artery. The comparatively lower incidence of aortic origin of the vertebral artery $(3.6 \%)$ is consistent with observations that incidences from imaging studies are lower than those from dissection studies (Keet et al., 2019). This article also highlights other clinically relevant variations of the vertebral artery. The findings underscore the need for vigilance during diagnostic and intervention cardiothoracic and neck surgical procedures in African population, in order to minimize iatrogenic injury and hemorrhage.

\section{REFERENCES}

1. Al - Okaili R, Schwartz ED, 2007. Bilateral aortic origins of the verterbral arteries with the right verterbral artery arising distal to left subclavian artery: Case Report. Surg Neurol, 67: $174-176$.

2. Einstein EH, Song LH, Villela NLA, Fasani - Felberg GB, Jacobs JL, Kim DO. 2016. Anomalous origin of left vertebral artery from the aortic arch, AORTA; 4: 64-67.

3. Gabrielli R, Rosati MS. 2013. Ataxia and Vertigo due to anomalous origin of the left vertebral artery. J Vasc Surg, 58: 803.

4. Keet K, Guston G, Alexander R. 2019. Variations in the branching pattern of the aortic arch: An African Perspective. Eur J Anat, 23: $91-102$.

5. Lale P, Toprak U, Yagz G, Kaya T, Uyanik SA, 2014. Variations in the branching pattern of the aortic arch detected with computerized tomography angiography. Adv Radiol, Vol 2014; ID969728.

6. Mutalife F, Sing'ombe I, Nambule V, Sikhanyiso M, Kafumukache E, Sunkutu V et al., 2019. Anatomical variations of the vertebral artery in a Zambian indigeneous adult population undergoing computerized tomography angiography at the University Teaching Hospitals Lusaka, Zambia. Anat J Afr; 8: 1486 1491.

7. Nathan H, Siedel MR. 1983. The association of retroesophageal right subclavian artery, a right - sided terminating thoracic duct, and a left vertebral artery of aortic origin: anatomical and clinical considerations. Acta Anat (Basel); 117: $362-373$.

8. Ogeng'o JA, Olabu BO, Gatonga PM, Munguti JK. 2010. Branching Pattern of aortic arch in a Kenyan population. J Morphol Sci, 27: $51-55$.

9. Panicker HK, Tarnecker A, Dhawane V, Ghosh SK. 2002. Anamalous origin of the left vertebral artery embryological basis and applied aspects. J Anat Soc India; 51: $234-235$.

10. Poonam R, Singla K, Sharma T. 2010. Incident of anomalous origins of vertebral artery - anatomical study and clinical significance. J Clin Diagn Res; 4: 2626 - 2631.

11. Ughade JM, Kardile PB, Ughade MN, Chaware PN, Pandit SV. 2012. Anomalous arch of the aorta giving rise to left vertebral artery. Int J Biol Med Res, 3: $2452-2454$.

12. Yamashiro S, Kuniyoshi Y, Arakaki K, Inafuku H, Morishima Y, Kise Y. 2010. Total arch replacement with associated anomaly of the left verterbral artery. Ann Thoracic Surg; 16: $216-219$.

13. Yuan S - M. 2016. Aberrant origin of Vertebral artery and its clinical implicatiuons. Braz J Cardiovasc Surg, 31: $52-59$. 